\title{
PENGARUH CRYOTHERAPY TERHADAP NYERI LUKA EPISIOTOMI PADA PASIEN POST PARTUM HARI PERTAMA DI RUANG PERAWATAN V/VI RS. DUSTIRA CIMAHI
}

\author{
CRYOTHERAPY EFFECT OF WOUND PAIN PATIENTS EPISIOTOMY POSTPARTUM \\ FIRST DAY IN THE TREATMENT V / VI RS. DUSTIRA CIMAHI
}

\author{
Asep Edyana ${ }^{1}$, Endah Sri Lestari ${ }^{2}$, Novi Malisa ${ }^{3}$ \\ Akademi Keperawatan RS.Dustira Cimahi. \\ Email: mellizaiesmail@yahoo.co.id ${ }^{1}$ \\ endahsrilestari@ymail.com² \\ novimalisa53@gmail.com ${ }^{3}$
}

\begin{abstract}
ABSTRAK
Pendahuluan: Nyeri merupakan keluhan tertinggi yang dirasakan pasien dengan luka episiotomi menyebabkan penurunan kemampuan ibu untuk melakukan bounding attachment kepada bayinya. Intervensi keperawatan yang dapat menurunkan keluhan nyeri luka episiotomy secara aman dan tanpa efeksamping menjadi penting. Tujuan: Penelitian ini bertujuan untuk mengetahui pengaruh cryptherapy terhadap nyeri luka episiotomi pada pasien post partum hari pertama di Ruang V/VI RS. Dustira Cimahi. Metode: Penelitian ini menggunakan metode penelitian quasi eksperimental dengan pendekatan two groups pretest and posttest design. Sebanyak 88 pasien dipilih sebagai responden yang terbagi dalam dua kelompok menggunakan accidental sampling. Data dianalisis menggunakan uji statistik analisis univariat (berupa distribusi frekuensi, persentase dan mean dari setiap variabel), analisis bivariat (paired $t$ test, independent $t$ test), dan analisis multivariat (uji ancova). Hasil: Penelitian menunjukkan bahwa terdapat perbedaan rerata skor nyeri antara skor sebelum dan sesudah dilakukan intervensi cryotherapy pada kelompok intervensi (pretest $4,86 \pm 0,930$ dan posttest 3,59 $\pm 0,844$ ). Pada kelompok kontrol juga terjadi penurunan skor nyeri setelah dilakukan relaksasi autogenik (pretest $4,86 \pm 0,930$ dan posttest $4,82 \pm 1,040$ ) namun peningkatan ini tidak signifikan. Terdapat perbedaan bermakna selisih skor nyeri kelompok intervensi dengan kelompok kontrol $(p=0,000)$. Tidak adanya pengaruh dominan yang signifikan $(p>0,005)$ dari masing-masing karakteristik responden (usia, skor cemas dan riwayat episiotomi sebelumnya) terhadap skala nyeri posttest kelompok intervensi. Secara umum hasil penelitian ini menemukan ada pengaruh cryotherapy terhadap tingkat nyeri luka episiotomy dibandingkan dengan relaksasi autogenik. Diskusi: Disarankan kepada pasien post partum yang mengalami luka nyeri episiotomy agar menggunakan tehni cryotherapy mulai hari pertama post partum, rutin dilakukan dua hari sekali (pagi dan sore) untuk mempercepat penurunan skala nyeri.
\end{abstract}

Kata Kunci: cryotherapy, nyeri luka episiotomi, post partum

\section{ABSTRACT}

Introduction: Pain is the highest complaint felt by a patient with episiotomy injury causing a decrease in the mother's ability to perform bounding attachment to her baby. Safe and less side effect interventions that aimed to reduce pain of episiotomy wound become necessary. Objective: This study aims to determine the effect of cryptherapy on the pain of episiotomy wound in first day postpartum patient in Room V / VI RS. Dustira Cimahi. Method: This research uses quasi experimental research method with approach of two groups pretest and posttest design. A total of 88 patients were selected as respondents who were divided into two groups using accidental sampling. Data were analyzed using univariate statistic test (frequency distribution, percentage and mean of each variable), bivariate analysis (paired t test, independent $t$ test), and multivariate analysis (ancova test). Results: This study indicates that there is a difference in the mean score of pain between before and after cryotherapy intervention

SKOLASTIK KEPERAWATAN

Vol. 2, No.2

Juli - Desember 2016

ISSN: $2443-0935$

E-ISSN: 2443 - 1699 
in the intervention group (pretest $4.86 \pm 0.930$ and posttest $3.59 \pm 0.844$ ). There is different in pain score after the autogenic relaxation in control group (pretest $4.86 \pm 0.930$ and posttest $4.82 \pm 1.040$ ) yet the increament is not statistically significant. There was a significant difference in intervention group pain score with control group ( $p=0,000)$. There is no significant influence ( $p>0.005)$ of each respondent characteristic (age, anxiety score and previous episiotomy history) on the posttest pain scale of the intervention group. In general, the results of this study found no effect of cryotherapy on the level of episiotomy wound pain compared with autogenic relaxation. Discussion: It is advisable for postpartum patients with episiotomy pain to use cryotherapy from the first day of post partum, routinely done every other day (morning and afternoon) to accelerate the decrease of pain scale.

Keywords: cryotherapy, episiotomy wound pain, post partum

\section{PENDAHULUAN}

Nyeri merupakan pengalaman subjektif, emosional, dan individual yang bersifat unik melibatkan respon secara fisiologis, kognitif, dan sosial. Nyeri merupakan alasan yang paling umum seseorang mencari bantuan perawatan kesehatan karena sangat mengganggu dan menyulitkan banyak orang (Briggs, 2010). Nyeri dapat bersifat persisten sehingga menjadi sumber berbagai masalah bagi kesehatan fisik maupun psikologis pasien. Oleh sebab itu, respon nyeri sangat penting untuk diketahui dan diinisiasi, terutama bagi seorang perawat. Nyeri dibedakan atas nyeri neuropatik yaitu nyeri yang disebabkan oleh lesi (kerusakan) sistem syaraf dan nyeri nosiseptif yaitu nyeri yang disebabkan oleh proses inflamasi dan kerusakan jaringan (Macintyre \& Schug, 2007).

Penyebab nyeri nosiseptif yang paling umum adalah karena proses inflamasi atau kerusakan jaringan sebagai contohnya karena fraktur, luka post operasi, ataupun luka karena prosedur tindakan seperti episiotomi. Episiotomi merupakan tindakan insisi perineum pada kala II persalinan untuk membantu proses pengeluaran bayi (American College of Obstetricans and Gynecology (ACOG), 2006). Lamanya proses penyembuhan tergantung kepada proses perbaikan jaringan, besarnya trauma jaringan dan digambarkan menurut persepsi nyeri yang dikeluhkan oleh pasien (McCandlish, 2001 dalam Gould, 2007). Pengkajian keluhan nyeri pasien pada fase awal setelah persalinan menjadi penting dan pelaksanaan tindakan untuk mengurangi nyeri yang dialami pasien dapat meningkatkan kenyamanan, mempercepat proses penyembuhan, dan meningkatkan kualitas hidup pasien terkait dengan percepatan proses adaptasi fisiologis pasien post partum (Hartman et al, 2005).

Strategi penatalaksanaan nyeri terdiri dari dua aspek yaitu farmakologis dan non farmakologis. Semua intervensi akan sangat berhasil bila dilakukan secara cepat dan tepat sebelum nyeri menjadi kronis dan hasil outcome menjadi lebih efektif jika beberapa intervensi diterapkan secara simultan (Smeltzer \& Bare, 2010). Berdasarkan hasil studi pendahuluan di Ruang Bersalin RS. Dustira, pasien yang melahirkan dengan status primipara dan pasien yang mengalami jaringan parut pada luka episiotomy terdahulunya lebih beresiko mendapatkan tindakan episiotomy. Hasil wawancara dengan 10 orang pasien yang mengalami episiotomi menggambarkan bahwa keluhan nyeri yang dialami pasien sangat mengganggu kenyamanan dan mengurangi tingkat kemandirian pasien sehingga diperlukan intervensi lain yang dapat lebih efektif untuk mengurangi keluhan tersebut.

Penatalaksanaan nyeri non farmakologis merupakan bentuk intervensi yang dapat meningkatkan self management pasien dan mengurangi ketergantungan pasien terhadap terapi farmakologis untuk mengatasi semua keluhan yang dialaminya. Salah satu intervensi non farmakologis untuk mengatasi nyeri adalah cryotherapy. Beberapa penelitian menjelaskan mengenai efek stimulasi kulit untuk menurunkan nyeri (Kubsch, Neveau \& Vandertie, 2000 dalam Sabitha, et al, 2008). Cryotherapy merupakan intervensi keperawatan mandiri 
yang dapat diadvokasikan untuk mengurangi keluhan nyeri pasien (Park, 1998 dalam Sabitha, et al, 2008). Sistem kerja cryotherapy memakai teori gate control yang mengaktivasi neurotransmitter endorfin, enkefalin, dan dinorfin (opium alami tubuh) untuk menutup gerbang penghantaran nyeri sehingga impuls nyeri di blok dan tidak dipersepsikan (Waters \& Raislers, 2003 dalam Sabitha, et al, 2008).

Efek cryotherapy terhadap penurunan nyeri sudah dibuktikan oleh beberapa penelitian, diantaranya : (1) Penelitian kuasi eksperimen terhadap 31 sampel mengenai efek cryotherapy terhadap nyeri kepala post ECT menjelaskan bahwa cryotherapy dapat digunakan untuk mengurangi nyeri kepala pasien yang telah menjalani ECT, (2) Sabitha, et al (2008) dalam penelitiannya yang berjudul "Effect of Cryotherapy on Arteriovenous Fistula Puncturerelated Pain in Hemodialysis Patients" membuktikan bahwa cryotherapy dapat menurunkan nyeri pada penusukan jarum di fistula pasien yang menjalani hemodialisis. Study literature menunjukan belum ada penelitian yang sejenis mengenai efek cryotherapy terhadap nyeri luka episiotomi.

\section{METODE PENELITIAN}

Penelitian ini menggunakan desain penelitian quasi experimental dengan rancangan two groups pretest and postest design. Penelitian yang dilakukan, meneliti pengaruh intervensi cryotherapy terhadap nyeri luka episiotomi. Intervensi cryotherapy dilakukan pada responden kelompok intervensi hari pertama post partum selama 15 menit sedangkan pada kelompok kontrol diberikan relaksasi autogenic selama 20 menit. Sampel penelitian untuk masing masing kelompok adalah 44 orang. Kelompok intervensi dan kelompok kontrol diambil dari RS. yang sama yaitu RS. Dustira Cimahi. Instrumen dalam penelitian ini terdiri dari instrumen protokol pelaksanaan cryotherapy, protokol pelaksanaan relaksasi autogenik, instrument pengukur skala nyeri numerik.

\section{HASIL PENELITIAN}

\section{Analisis Univariat}

Karakteristik responden membahas mengenai usia, skala cemas dan pengalaman episiotomi sebelumnya. Dalam karakteristik responden juga menggambarkan hasil uji homogenitas data kelompok intervensi dengan kelompok kontrol.

Tabel 1 Distribusi frekuensi, persentase dan uji homogenitas karakteristik responden kelompok intervensi dan kelompok kontrol $(n=88)$

\begin{tabular}{|c|c|c|c|c|c|}
\hline \multirow{2}{*}{ Karakteristik } & \multicolumn{2}{|c|}{ Intervensi $(n=44)$} & \multicolumn{2}{|c|}{ Kontrol $(n=44)$} & \multirow{2}{*}{ Nilai $P$} \\
\hline & $f$ & (\%) & $f$ & $(\%)$ & \\
\hline \multicolumn{6}{|l|}{ Usia (Tahun) } \\
\hline $17-25$ & 24 & 54,5 & 21 & 47,7 & $0,831^{a}$ \\
\hline $26-45$ & 20 & 45,5 & 23 & 52,3 & \\
\hline \multicolumn{6}{|l|}{ Skala Cemas } \\
\hline Tidak cemas & 9 & 20,5 & 9 & 20,5 & \\
\hline Cemas ringan & 21 & 47,7 & 20 & 45,5 & $1,000^{b}$ \\
\hline Cemas sedang & 9 & 20,5 & 10 & 22,7 & \\
\hline Cemas berat & 5 & 11,4 & 5 & 11,4 & \\
\hline \multicolumn{6}{|c|}{$\begin{array}{l}\text { Pengalaman episiotomi } \\
\text { sebelumnya }\end{array}$} \\
\hline Ya & 9 & 20,5 & 9 & 20,5 & $0,604^{a}$ \\
\hline Tidak & 35 & 79,5 & 35 & 79,5 & \\
\hline
\end{tabular}


*a : Chi Square

*b : Man Whitney

Berdasarkan tabel 1 di atas, diketahui bahwa rentang usia responden yang paling banyak pada kelompok intervensi adalah 17-25 (54,5\%) sedangkan pada kelompok kontrol adalah rentang usia 26-45 (45,5\%). Skala cemas yang paling dominan pada kelompok intervensi maupun kelompok kontrol adalah cemas ringan dan sebagian besar $(79,5 \%)$ dari responden kelompok intervensi maupun kelompok kontrol tidak mempunyai pengalaman episiotomi sebelumnya.

Hasil uji homogenitas semua karakteristik menunjukan nilai sig. (signifikansi) >0,05 yang memiliki arti bahwa sebaran data pada kelompok intervensi dan kelompok kontrol adalah homogen.

Tabel 2 Hasil uji homogenitas skor nyeri pada kelompok intervensi dan kelompok kontrol sebelum dilakukan Intervensi $(n=88)$

\begin{tabular}{lccccc}
\hline Karakteristik & \multicolumn{2}{c}{ Intervensi $(\mathbf{n}=44)$} & \multicolumn{2}{c}{ Kontrol $(\mathbf{n}=44)$} & Nilai $\boldsymbol{p}$ \\
\hline $\begin{array}{l}\text { Skor Nyeri } \\
\text { Pretest }\end{array}$ & Mean & SD & Mean & SD & \\
\hline
\end{tabular}

${ }^{\star}$ a : Independent t-test

Tabel 2 menunjukan rata-rata skor nyeri pretest pada kelompok intervensi dan kelompok kontrol adalah 4,86. Berdasarkan uji homogenitas skor nyeri, tidak berbeda antara kelompok intervensi dan kontrol dengan nilai $p>0,05$.

\section{Analisis Bivariat}

Analisis bivariat untuk mengetahui apakah ada perbedaan rerata tingkat nyeri pada kelompok intervensi dengan kelompok kontrol. Karena data berdistribusi normal maka untuk analisis bivariat menggunakan uji t paired untuk mengetahui perbedaan rerata pre post test pada kelompok intervensi dan kontrol, sedangkan untuk mengetahui perbedaan rerata skor nyeri pretest dan posttest kelompok intervensi dan kontrol serta untuk mengetahui selisih pretest dan posttest skor nyeri menggunakan independent $t$ test.

Tabel 3 Distribusi frekuensi tingkat nyeri sebelum dan sesudah intervensi pada kelompok intervensi dan kelompok kontrol $(n=88)$

\begin{tabular}{lcccc}
\hline \multicolumn{1}{c}{ Pengukuran } & \multicolumn{2}{c}{ Intervensi $(\mathbf{n = 4 4 )}$} & & Kontrol \\
\cline { 2 - 5 } & $(\mathbf{n = 4 4 )}$ & $\boldsymbol{f}$ & $\boldsymbol{f})$ & $(\%)$ \\
\hline Pretest & & & & \\
$\quad$ Ringan & 3 & 6,8 & 3 & 6,8 \\
$\quad$ Sedang & 41 & 93,2 & 41 & 93,2 \\
$\quad$ Berat & - & - & - & - \\
$\quad$ Total & $\mathbf{4 4}$ & $\mathbf{1 0 0}$ & $\mathbf{4 4}$ & $\mathbf{1 0 0}$ \\
\hline $\begin{array}{l}\text { Posttest } \\
\text { Ringan }\end{array}$ & & & & \\
\hline
\end{tabular}




\begin{tabular}{lcccc}
\hline Sedang & 24 & 54,5 & 41 & 93,2 \\
Berat & - & - & - & - \\
Total & $\mathbf{4 4}$ & $\mathbf{1 0 0}$ & $\mathbf{4 4}$ & $\mathbf{1 0 0}$ \\
\hline
\end{tabular}

Berdasarkan tabel 3 diketahui bahwa setelah dilakukan intervensi cryotherapy pada kelompok intervensi terjadi perbaikan skala nyeri responden yaitu sebanyak 17 orang menjadi ringan dari skala sedang. Sementara pada kelompok kontrol, tidak ada perubahan kategori skala nyeri setelah dilakukan relaksasi autogenik.

Tabel 4 Perbedaan rerata skor nyeri pretest kelompok intervensi dan kontrol

\begin{tabular}{lcccc}
\multicolumn{1}{c}{ Variabel } & Mean & SD & $\boldsymbol{t}$ & $\boldsymbol{p}$ \\
\hline Skor Nyeri & & & & \\
Intervensi & 4,86 & 0,930 & 0,000 & $1,000^{\mathrm{a}}$ \\
Kontrol & 4,86 & 0,930 & & \\
\hline
\end{tabular}

*a : Independent t-test

Berdasarkan tabel 4 di atas diketahui bahwa tidak ada perbedaan skor nyeri sebelum intervensi antara kelompok

intervensi dengan kelompok kontrol ditandai dengan nilai $p>0,05$.

Tabel 5 Perbedaan rerata skor nyeri posttest pada kelompok intervensi dan kontrol

\begin{tabular}{lcccc}
\hline \multicolumn{1}{c}{ Variabel } & Mean & SD & $\boldsymbol{t}$ & $\boldsymbol{p}$ \\
\hline $\begin{array}{l}\text { Skor Nyeri } \\
\text { Intervensi }\end{array}$ & 3,59 & 0,844 & $-6,076$ & $0,000^{\mathrm{a}}$ \\
Kontrol & 4,82 & 1,040 & & \\
\hline
\end{tabular}

${ }^{*} \mathrm{a}:$ Independent t-test

Berdasarkan tabel 5 di atas diketahui bahwa ada perbedaan secara signifikan skor nyeri sesudah intervensi antara kelompok intervensi dan kelompok kontrol dengan nilai $p 0,000$.

\section{Tabel 6 Perbedaan rerata skor nyeri pretest dan posttest kelompok intervensi}

\begin{tabular}{lcccc}
\multicolumn{1}{c}{ Variabel } & Mean & SD & $\boldsymbol{t}$ & $\boldsymbol{p}$ \\
\hline Skor Nyeri & & & & \\
$\begin{array}{l}\text { Pretest } \\
\text { Posttest }\end{array}$ & 4,86 & 0,930 & 18,739 & $0,000^{\mathrm{b}}$ \\
\hline
\end{tabular}

${ }^{*} \mathrm{~b}$ : Paired t-test

Berdasarkan tabel 6 di atas diketahui bahwa terjadi perubahan signifikan skor nyeri sebelum dan sesudah pada kelompok kontrol dengan nilai $p 0,000$. 
Tabel 7 Perbedaan rerata skor nyeri pretest dan posttest kelompok kontrol

\begin{tabular}{lcccc}
\multicolumn{1}{c}{ Variabel } & Mean & SD & $\boldsymbol{t}$ & $\boldsymbol{p}$ \\
\hline Skor Nyeri & & & & \\
$\begin{array}{l}\text { Pretest } \\
\text { Posttest }\end{array}$ & 4,86 & 0,930 & 1,431 & $0,160^{\mathrm{b}}$ \\
\hline
\end{tabular}

*b : Paired t-test

Berdasarkan tabel 7 di atas diketahui bahwa tidak terjadi perubahan signifikan skor nyeri sebelum dan sesudah intervensi pada kelompok intervensi dengan nilai $p$ 0,160 .

Tabel 8 Perbedaan selisih rerata skor nyeri pada kelompok intervensi dan kontrol

\begin{tabular}{lcccc}
\hline \multicolumn{1}{c}{ Variabel } & $\Delta$ Mean & SD & $\boldsymbol{t}$ & $\boldsymbol{p}$ \\
\hline Skor Nyeri & & & & \\
Intervensi & 1,27 & 0,451 & $-4,667$ & $0,000^{\mathrm{a}}$ \\
Kontrol & 0,05 & 2,111 & $-4,667$ & \\
\hline
\end{tabular}

${ }^{*} \mathrm{a}:$ Independent t-test

Berdasarkan tabel 8 di atas diketahui bahwa terdapat perbedaan selisih mean skor nyeri sebelum dan sesudah intervensi pada kelompok intervensi dan kelompok kontrol. Nilai mean kelompok intervensi dan kontrol bernilai positif yang artinya terjadi penurunan skor nyeri setelah intervensi, dimana pada kelompok intervensi penurunan skor nyeri ke arah yang lebih baik rata-rata 1,27. Angka ini lebih besar dibandingkan penurunan skor nyeri pada kelompok kontrol yang hanya 0,05 . Secara statistik, terdapat perbedaan secara signifikan selisih skor nyeri antara kelompok intervensi dengan kelompok kontrol $(p=0,000)$.

\section{Analisis Multivariat}

Analisis multivariat ini untuk mengetahui/melihat pengaruh perlakuan terhadap peubah respon (skala nyeri) dengan mengontrol peubah lain yang kuantitatif seperti usia dan tingkat stres.

Tabel 9 Analisis pengaruh karakteristik responden terhadap skala nyeri posttest pada kelompok intervensi.

\begin{tabular}{lccc}
\hline \multicolumn{1}{c}{ Variabel } & $\boldsymbol{F}$ & $\boldsymbol{p}$ & Corrected model \\
\hline Usia & 0,486 & 0,490 & 0,032 \\
Skor Cemas & 7,873 & 0,008 & \\
Riwayat episiotomi & 0,331 & 0,568 & \\
sebelumnya & & & \\
\hline
\end{tabular}

Tabel 9 menunjukan tidak adanya pengaruh dominan yang signifikan $(p>0,005)$ karakteristik responden (usia, skor cemas dan riwayat episiotomy sebelumnya) terhadap skala nyeri posttest kelompok intervensi yang mengindikasikan bahwa tidak ada variabel karakteristik responden yang dominan dapat mempengaruhi skala nyeri posttest kelompok intervensi. Variabel karakteristik responden ini hanya dapat berpengaruh terhadap skala nyeri posttest kelompok intervensi secara bersamaan. Hal ini dapat dilihat dari nilai $p$ corrected model yaitu 0,032 . 


\section{PEMBAHASAN}

Penelitian ini bertujuan untuk mengidentifikasi pengaruh Cryotherapy terhadap nyeri luka episiotomi pasien post partum hari pertama di Ruang V/VI RS. Dustira Cimahi. Secara umum tingkat nyeri sebelum intervensi yang dialami oleh kelompok intervensi dan kelompok control berada pada tingkat sedang $(93,2 \%)$ dengan rata-rata skor 4,86. Setelah dilakukan intervensi Cryotherapy, terjadi penurunan skor nyeri dengan rata-rata penurunan 1,27 menjadi 3,56. Dari hasil analisis korelasi paired t test, terjadi perubahan skor nyeri yang signifikan $(p<$ 0,05 ) pada kelompok intervensi. Signifikansi perubahan skor nyeri setelah dilakukan intervensi Cryotherapy ini sejalan dengan hasil penelitian Waters \& Raislers (2003) dalam Sabitha, et al (2008) yang menyatakan bahwa cryotherapy dapat mengurangi aktivitas metabolisme dalam jaringan sehingga mencegah kerusakan jaringan sekunder dan mengurangi sinyal nyeri ke sistem saraf pusat.

Wulandari (2012) menyatakan dalam penelitiannya bahwa respon fisiologis pertama dari jaringan pada cryotherapy adalah penurunan suhu lokal yang menyebabkan penurunan metabolisme sel. Reseptor suhu terangsang oleh perubahan kecepatan metabolik yang disebabkan oleh suhu sehingga menurunkan suhu jaringan yang rusak melalui pertukaran panas dan menyempitkan pembuluh darah. Hal ini memperlambat metabolisme dan konsumsi oksigen sehingga mengurangi kerusakan sel. Pernyataan ini diperkuat dengan hasil penelitian Brian, et al (2005) yang menemukan pengaruh cryotherapy terhadap penurunan keluhan nyeri kepala pada pasien yang telah menjalani ECT dan juga hasil penelitian Sabitha, et al (2008) mengenai pengaruh cryotherapy terhadap penurunan nyeri pada penusukan fistula.

Pada saat pelaksanaan cryotherapy ini, semua responden tidak mengalami kesulitan selain itu tidak terjadi efek samping dari semua pelaksanaan cryotherapy pada semua responden di kelompok intervensi. Prosedur pelaksanaan cryotherapy pada penelitian ini adalah melakukan kompres es dengan suhu 70 selama 15 menit dan terbukti dapat menurunkan skor nyeri secara signifikan seperti yang dijelaskan oleh Crystal, Townson. Cook, \& LaRoche (2013) bahwa suhu es yang efektif untuk mengurangi inflamasi adalah tidak lebih dari 70 dan pernyataan lain yang mendukung dalam protokol cryotherapy ini adalah pernyataan Lisa, et al (2012) bahwa lama pelaksanaan cryotherapy disesuaikan dengan ketebalan otot yang akan diterapi, dikarenakan tebal otot perineum pada umumnya 10-12 mm sehingga lama pelaksanaan cryotherapy yang dianjurkan adalah 15-25 menit.

Sama halnya dengan skor nyeri sebelum intervensi pada kelompok intervensi, secara umum tingkat nyeri sebelum intervensi yang dialami oleh kelompok kontrol berada pada tingkat sedang $(93,2 \%)$ dengan rata-rata skor 4,86. Pada skor nyeri setelah intervensi relaksasi autogenic terjadi penurunan rata-rata sebesar 0,05 menjadi 4,82 . Walaupun terjadi penurunan, tetapi dari hasil analisis korelasi paired t test, tidak terjadi perubahan yang signifikan $(p<0,05)$ antara skor nyeri sebelum dan sesudah di kelompok kontrol.

Perubahan skor nyeri yang terjadi pada kelompok kontrol ini diperkirakan karena adanya pengaruh dari intevensi relaksasi autogenik seperti yang ditemukan dalam penelitian Nurhayati, Andriani, Malisa (2015) bahwa relaksasi autogenic dapat menurunkan nyeri luka post operasi saecarea. Relaksasi Autogenik merupakan relaksasi yang bersumber pada diri sendiri dengan menggunakan kata-kata pendek yang mampu memberikan pengaruh sehingga menyebabkan pikiran seseorang menjadi tenang (Pratiwi, 2012). Autogenik secara spesifik mengisyaratkan bahwa kita mampunyai kemampuan untuk mengendalikan berbagai fungsi tubuh, misalnya saja frekuensi denyutan jantung, 
aliran darah, tekanan darah, peristaltik usus. Fokus dari relaksasi autogenik ini adalah belajar untuk mengalihkan pikiran berdasarkan perintah sehingga mampu menghilangkan respon stres yang dapat mengganggu pikiran, yang menjadi inti dari tehnik relaksasi autogenik adalah penyerahkan kepada diri sendiri (Setyawati, 2010).

Efek relaksasi autogenik pada kelompok kontrol ini tidak signifikan menurunkan nyeri karena pelaksanaan relaksasi autogenik hanya sekali, sedangkan relaksasi autogenik dapat berpengaruh terhadap penurunan nyeri jika dilakukan berulangulang, rutin dan tidak dalam waktu yang cepat seperti halnya penelitian Zsombok (2007) yang menggabungkan terapi relaksasi autogenik dengan organ formula dan motion therapy untuk mengatasi masalah sakit kepala dan migrain, efek relaksasi autogenik tampak pada kelompok intervensi dimana dalam waktu 3 bulan menunjukkan angak serangan migrain dan sakit kepala berkurang. Berdasarkan hasil penelitian ini dianjurkan untuk mendapatkan pengaruh relaksasi autogenik terhadap penurunan nyeri dilakukan dengan rutin dan berulang ulang.

Merujuk pada hasil analisis selisih mean skor nyeri pada kelompok intervensi dan kontrol, terdapat signifikansi perbedaan selisih skor nyeri antara kelompok intervensi dengan kelompok kontrol dengan nilai $p=$ 0,000 . Pelaksanaan Cryotherapy ini dianjurkan dilakukan rutin dua kali sehari. Penurunan skor nyeri pada kelompok intervensi tidak dipengaruhi oleh usia, tingkat kecemasan dan pengalaman episiotomi sebelumnya dilihat dari hasil analisis multivariat yang menunjukan tidak adanya pengaruh dominan yang signifikan ( $p>0,005$ ) karakteristik responden (usia, skor cemas dan riwayat episiotomy sebelumnya) terhadap skala nyeri posttest kelompok intervensi.

Hasil penelitian ini menemukan ada pengaruh Cryotherapy terhadap tingkat nyeri luka episiotomi pasien post partum hari pertama, sehingga Cryotherapy ini dapat dijadikan sebagai intervensi keperawatan mandiri dalam pengelolaan nyeri luka episiotomi.

\section{SIMPULAN}

Secara umum hasil penelitian ini menemukan ada pengaruh Cryotherapy terhadap tingkat nyeri luka episiotomi pasien post partum hari pertama.

\section{SARAN}

Cryotherapy dapat dijadikan bahan masukan sebagai pertimbangan intervensi keperawatan mandiri yang dapat dilakukan oleh perawat untuk menurunkan tingkat nyeri luka episiotomi. Selain itu hasil penelitian ini dapat dijadikan sebagai salah satu evidance based nursing yang dijadikan landasan rasional pelaksanaan Cryotherapy sebagai intervensi keperawatan mandiri untuk mengurangi tingkat nyeri luka episiotomi.

\section{DAFTAR PUSTAKA}

American Colledge of Obstetricans and Gynecologists. (2006). ACOG Bulletin No. 71 : Episiotomy. Clinical Management Guidelines for Obstetricans/Gynecologists.

Obstetrics and Gynecology. 107(4), 957-962.

Arikunto, S. (2010). Prosedur Penelitian Suatu Pendekatan Praktik. Jakarta: Rineka Cipta.

Ariyanto. (2009). Pengelolahan dan Analisis Data Kesehatan. Yogyakarta: Nuha medika.

Asmadi, (2008). Kebutuhan Dasar Manusia. Jakarta : EGC

Bauer M. (2006). The P nal days of traditional beliefs. Chinese Medicine Times(1):4 
Bleakley, C. M., McDonough, S. M., \& MacAuley, D. C. (2006). Cryotherapy for acute ankle sprains: A randomised controlled study of two different icing protocols. British Journal of Sports Medicine, 40(8), 700.

doi:http://dx.doi.org/10.1136/bjsm.20 06.025932

Briggs, E. (2010). Assessment and expression of pain. Nursing Standard $25 \mathrm{pg} 35-38$.

Briggs E. (2010). Understanding the experience and physiology of pain. Nursing Standard, 25(3), 35-39. Date of acceptance: January 182010

Bulechek, G.M., Butcher, H.K., \& Dochterman, J.M. (Ed.). (2008). Nursing interventions classification (nic): Fifth edition. USA: Elsevier

Cox, F. (2010). Basic principles of pain management: assessment and intervention. Nursing Standard. 25, 1, 36-39. Date of acceptance: February 82010.

Crystal, N.J., Townson, D.H., Cook, S.B., \& LaRoche, D.P. (2013). Effect of cryotherapy on muscle recovery and inflammation following a bout of damaging exercise. Eur $J$ Appl Physiol, 113:2577-2586. DOI 10.1007/s00421-013-2693-9

Dahlan, S.M. (2011). Statistik untuk kedokteran dan kesehatan. Jakarta: Salemba Medika.

Dahlan, S.M. (2009). Statistik untuk kedokteran dan kesehatan. Jakarta: Salemba Medika.

Dharma, K.K. (2011). Metodologi Penelitian Keperawatan (Pedoman Melaksanakan dan Menerapkan Hasil Penelitian). Jakarta : Trans Info Media
El Hamid, Nagwa Abd El,Fadeel Abd, Obaya, H. E., \& Gaafar, H. M. (2013). Effect of acupressure on labor pain and duration of delivery among laboring women attending cairo university hospital. Indian Journal of Physiotherapy and Occupational Therapy, 7(2), 71-76. Retrieved from http://search.proquest.com/docview/ $\underline{1428297288 ? \text { accountid }=48290}$

Gloth, F., Scheve, A. A., Stober, C. V., Chow, S., Prosser, J. (2011). The functional pain scale: reliability, validity and responsiveness in an elderly population. Journal of the American Medical Directors Association, 2 (3), 110-114.

Gould, D. (2007). "Perineal tears and episiotomy." Nursing Standard 21(52): 41-46.

Hartman $K$, Vistwanathan $M$, Palmieri $R$, GArtiehner G, Throp J, Lohr KN. (2005). Outcomes of Routine Episiotomy : a Systematic Review. Journal of the American Medical Association. 293, 17, 2141-2148.

Herdman, T.H. (2012). NANDA international nursing diagnoses: Definition \& classification 2012-2014. Oxford: Wiley-Blackwell

Hidayat, A. (2009). Metode penelitian keperawatan dan analisis data. Jakarta : Salemba Medika

Jeffs, D. A. (2004). Self-selected distraction for acute procedural pain in adolescents: An intervention feasibility study (Order No. 3152709). Available from ProQuest Public Health. (305175853). Retrieved from http://search.proquest.com/docview/ $\underline{305175853 \text { ? accountid }=48290}$

Levett, K. M., Smith, C. A., Dahlen, H. G., \& Bensoussan, A. (2014). Acupuncture and acupressure for pain 
management in labour and birth: $A$ critical narrative review of current systematic review evidence. Complementary Therapies in Medicine, 22(3), 523-40. doi:http://dx.doi.org/10.1016/j.ctim.20 14.03.011

Lewis, S. M., Dirksen, S. R., Heitkemper, M. M., \& Bucher, L. (2007). MedicalSurgical Nursing: Assessment and Management of Clinical Problems. 7th ed. St. Louis: Mosby

Jutte, L. S., et al. (2012). "Skinfold Thickness at 8 Common Cryotherapy Sites in Various Athletic Populations." Journal of Athletic Training 47(2): 170-177.

Macintyre PE, Schug SA. (2007). Acute Pain Management: A Practical Guide. Third edition. Saunders Elsevier, Edinburgh.

Notoatmodjo, S. (2007). Metodologi Penelitian Kesehatan. Jakarta: Rineka Cipta.

Nurhayati, N.A., Andriani, S., \& Malisa, N. (2015). Pengaruh relaksasi autogenik terhadap penurunan skala nyeri pada ibu post operasi sectio saecarea di Ruang Perawatan V/VI RS. TK. II Dustira Cimahi. Jurnal Skolastik Keperawatan, 1(2), 52-61.

Oberwalder, et al. (2004). Anal Ultrasound and endosonographic measurement of perineal body thickness : a new evaluation for fecal incontinence infemale. Surg Endosc. Apr; 18(4):650-4. Epub 2004 Mar 19.

Pratiwi. (2012). Pengaruh teknik relaksasi autogenik terhadap penurunan tingkat kecemasan pada ibu dengan anak retardasi mental tingkat sedang di SDLB YAKUT Purwokerto. Skripsi pada Universitas Jenderal Soedirman Purwokerto
Polit, D. F., \& Beck, C. T. (2008). Nursing research: Generating and assessing evidence for nursing practice. Lippincott Williams \& Wilkins.

Potter \& Perry. (2006). Buku ajar fundamental keperawatan konsep, proses, dan praktik (ed.4, vol 2). Jakarta : EGC.

Sabitha, P., et al. (2008). "Effect of cryotherapy on arteriovenous fistula puncture-related pain in hemodialysis patients." Indian Journal of Nephrology 18(4): 155-158.

Setyawati, A., Sitorus, R., \& Sri, T. (2010). Pengaruh relaksasi autogenik terhadap kadar gula darah dan tekanan darah pada klien diabetes mellitus tipe 2 dengan hipertensi di Instalasi Rawat Inap Rumah Sakit D.I. Yogyakarta dan Jawa Tengah.

Smeltzer, S. C, \& Bare, B.G. (2010). Buku ajar keperawatan medikal bedah. Jakarta : EGC.

Smeltzer, S. C., Bare, B. G., Hinkle, J. L., \& Cheever, K. H. (2010). Brunner \& suddarth textbook of medical-surgical nursing. Philadelphia: Lippincott Williams \& Wilkins.

Wood, M. J., \& Ross-Kerr, J. C. (2011). Basic Steps in Planning Nursing Research (7th ed.). United States of America: Jones and Bartlett Publishers.

Wulandari. (2012). Pengaruh krioterapi terhadap pembengkakan, nyeri dan trismus pasien post odontektomi molar tiga. http://repository.usu.ac.id/handle/12 3456789/33223. 